Article

\title{
A New Trend in the Space-Time Distribution of Cultivated Land Occupation for Construction in China and the Impact of Population Urbanization
}

\author{
Kai Li®, Zhili Ma * and Jinjin Liu \\ School of Management Science and Real Estate, Chongqing University, Chongqing 400045, China; \\ 20170313002t@cqu.edu.cn (K.L.); 20160313007@cqu.edu.cn (J.L.) \\ * Correspondence: mzlmx@cqu.edu.cn; Tel.: +86-1590-236-4142
}

Received: 22 August 2019; Accepted: 14 September 2019; Published: 17 September 2019

\begin{abstract}
Rapid urbanization has brought huge development dividends to China. At the same time, its negative effects have aroused people's attention. For example, a large amount of cultivated land has been occupied for urban expansion and construction. Using exploratory spatial data analysis (ESDA) and the spatial Durbin model (SDM), we analyzed the spatial distribution of cultivated land occupation for construction (CLOC) and its driving factors in 31 provinces in China from 2005 to 2016. The results indicated that (1) the CLOC rate presented a significant spatial clustering feature, and its distribution showed a new trend of "homogenization" after the year 2012; (2) as the core driving factor, the population urbanization rate significantly promoted the growth of the CLOC rate in the local province, while showing a negative effect on that rate in the neighboring provinces; (3) in addition, behind the new trend of the CLOC rate, there was a transformation from being "investment driven" to being "population and industry driven". Therefore, this paper suggests that the government should link each city's construction land supply to the constantly changing trend of population migrations in China. Further, promoting the tertiary industry can be a win-win strategy for easing the tension between cultivated land and construction land.
\end{abstract}

Keywords: cultivated land loss; urban sprawl; population urbanization; sustainable urbanization; exploratory spatial data analysis; spatial econometrics

\section{Introduction}

A cultivated land resource is an indispensable natural resource foundation to support social and economic development. Its scarcity determines the fierce competition between different uses and sectors, leading to different resource allocation states [1]. Cultivated land occupation for construction (CLOC), as a specific manifestation of China's urbanization, reflects the result of the competition between cultivated land and urban construction land [2]. Rapid economic growth and constant population migrations are believed to be the main reasons for the continuous expansion of the scale of urban construction in China [3,4]. From 1981 to 2017, the average annual growth rate of urban construction land in China reached 6.02\% (calculated with data from the National Bureau of Statistics of China, available at http://data.stats.gov.cn/english/). However, the rapid expansion of urban land inevitably introduced the problem of cultivated land loss. As shown in Figure 1, from 2005 to 2016, the change in urban construction land and CLOC area showed an obvious correlation. In response to the shrinkage of cultivated land and threats to food security, the Chinese government has taken a series of measures, including setting the red line for cultivated land protection, reclaiming cultivated land in other places, and adjusting the supply of construction land quotas [5,6]. At the same time, the government still needs to promote the development of new urbanization and infrastructure 
construction, to ensure economic stability and improve domestic livelihood issues (narrowing the urban-rural gap and increasing employment in poor areas). Therefore, issues related to the game relationship between cultivated land and construction land are becoming the focus of scholarly attention, including the driving forces of urban expansion [4,7], the chain effect of cultivated land loss $[8,9]$, and the transformation from cultivated land into construction land $[10,11]$.

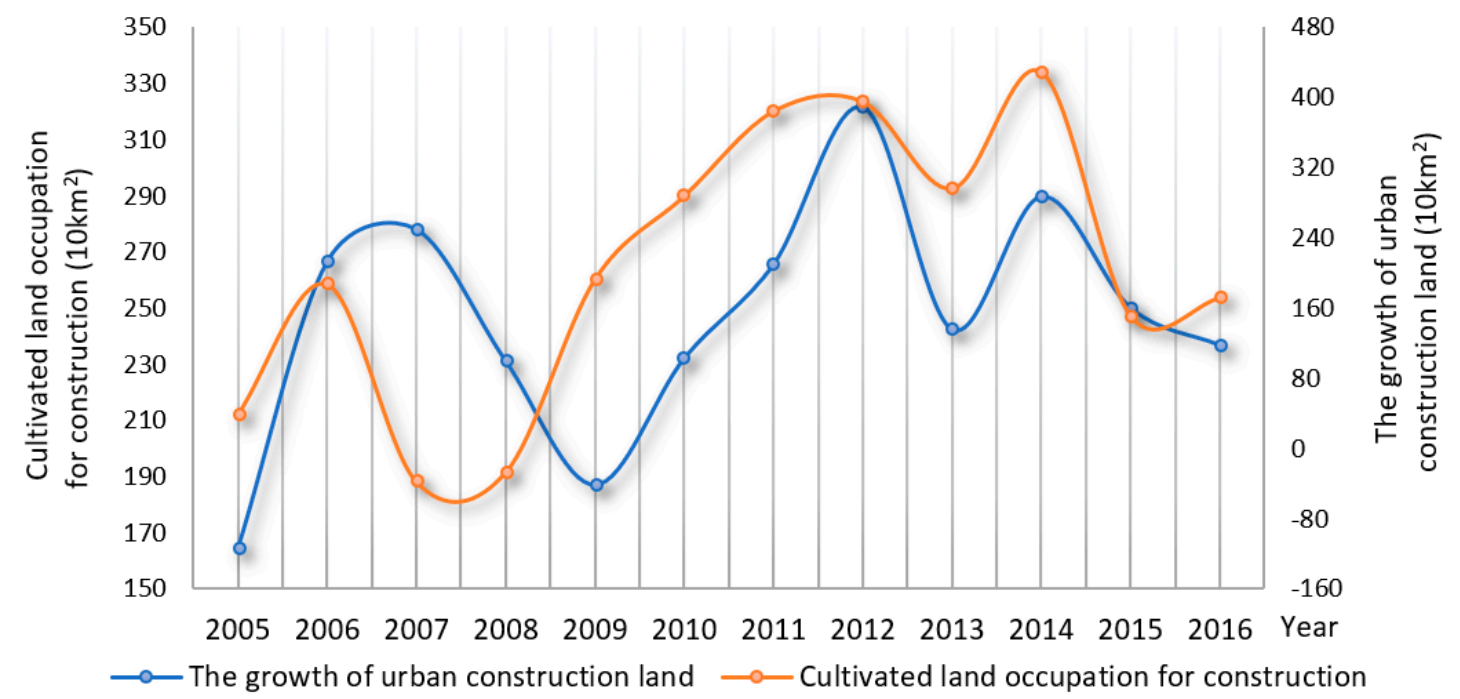

Figure 1. A close relationship between urban construction land and cultivated land occupation for construction. Data are from the Chinese land and resources statistical yearbook (2006-2017).

To make an accurate forecast for city planning or environmental protection, many studies have been devoted to exploring the space-time distribution of the conversion between cultivated land and construction land. For a single province or city, urban sprawl in the form of a big pancake was considered to be an accurate reflection of the current situation in China [6,12]. At the level of the urban agglomerations, the situation of economic development tends to have a close relationship with the CLOC [13]. For example, economically developed urban agglomerations, such as Beijing-Tianjin-Hebei, the Yangtze River Delta, and the Pearl River delta, were also regarded to be hot spots for urban expansion [14]. On the other hand, scholars have frequently discussed the driving factors of the CLOC. In a limited living space, there is no denying that human activities are restrained by natural resources, social economy, institutions, etc. Some previous studies suggested that the problem of China's cultivated land occupation is mainly driven by economic and demographic factors $[15,16]$. For example, Liu et al. (2005) argued that population urbanization, economic structures, and economic policies were crucial to land conversion during China's economic reform period (1990-2000) [15].

With their deepening understanding of new urbanization, scholars have realized that the driving factors of the CLOC are diverse and complex and include effects from natural and geographical conditions, such as the topography, altitude, and distance from commercial centers or administrative regions $[6,17,18]$, as well as other social and economic factors, including industrial structures [19], the urban-rural income gap [4], social welfare differences [20], population migration [21], and neighboring cities' effects [2]. Obviously, discussions on the spatial distribution and the driving forces of the CLOC are still ongoing, but there are several more meaningful issues that deserve our attention. How does the spatial distribution of the CLOC change with time? Are the driving factors of the CLOC fixed or dynamically adjusted? Previous research retained some limitations in answering these two questions. First, with a small amount of discontinuous data in a relatively long time-span, some research cannot describe the change in the CLOC accurately. Remote sensing images are widely used in the analysis of cultivated land loss and urban sprawl, but sometimes the images between two time points are separated by 5 or even 10 years due to the data collection cycle $[18,22]$, so it remains difficult to precisely grasp the subtle changes in the space-time distribution of the CLOC. 
Second, the influence of neighboring cities or regions on the subjects has been ignored. Even if the research object was a single city or a city agglomeration, its expansion behavior could be positively or negatively influenced by neighboring cities, and this influence is closely related to the location of the research object $[17,21]$. Third, the spatial spillover effect of the driving factors has not received enough attention-that is, the indirect influence of the driving factors from the neighboring regions has been neglected in the research due to the omission of spatial variables in the initial model settings, thus reducing the reliability of the research conclusions [4,23].

Sustainable development has become the dominant principle of global development. New urbanization needs to establish the concept of sustainable land planning and embed it in the process of urbanization development [24]. Based on the aim of sustainable urbanization, this study focused on two major issues: (1) changes in the space-time distribution of the CLOC in 31 provinces in China from 2005 to 2016; (2) how the driving factors affect the CLOC for both the local and neighboring provinces (in this paper, "local province" means one single province itself, and "neighboring provinces" indicates other provinces that are geographically adjacent or economically associated to one province), and how these factors vary with the new changes in the distribution of the CLOC. For issue (1), we used exploratory spatial data analysis (ESDA) to explore the spatial characteristics and the changes in the CLOC rate in Section 3.1, which includes an outlier analysis, global spatial autocorrelation analysis, and local spatial autocorrelation analysis. In addition, the spatial Dubin model (SDM) was adopted to address issue (2) in Section 3.2. The conclusions for the new distribution of the CLOC and its driving factors were discussed in Sections 4.1 and 4.2, respectively, followed by some suggestions on easing the contradiction between the cultivated land and the construction land in Section 4.3. Finally, conclusions about the research's methods and outputs are laid out in Section 5.

\section{Materials and Methods}

\subsection{Materials}

\subsubsection{Study Area}

This study took 31 Chinese provinces as research objects, including all Chinese provinces except Hong Kong, Macao, and Taiwan. In order to highlight the interaction effects between provinces, this study does not use the method that divides China into the east, middle, and western regions, as many studies have done. The relative positions of the 31 provinces are shown in Figure 2, with the abbreviation of each province in brackets. Note that a single province is a research unit in the following analysis. The division of areas with different colors is only to clearly show the position of the provinces in China.

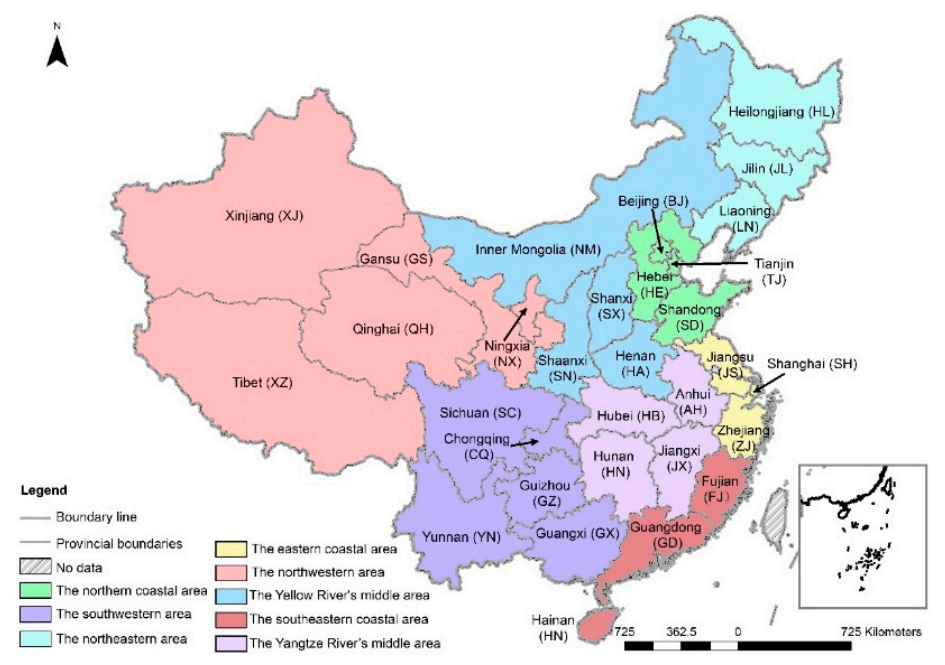

Figure 2. The position of the 31 provinces in China. 
2.1.2. An Analysis Framework of the Driving Factors of Cultivated Land Occupation for Construction (CLOC)

For the variable that can accurately describe the level of the CLOC, we adopted the concept of the CLOC rate [25]. We calculated this variable by the ratio between the CLOC area and the total cultivated land area. Some scholars have directly used the urban expansion area or the cultivated land loss area to measure and evaluate the CLOC level because such data could be acquired by remote sensing images $[6,22]$. However, except for the discontinuity of the data collection mentioned above, such kinds of variables are not able to consider all the cultivated land resources in each province, because a high CLOC level depends not only on the CLOC area but also on the total cultivated land area for each space unit [25].

The process of the CLOC is actually a trade-off between cultivated land and urban construction land in urbanization [26]. Therefore, the problem of the CLOC can be transformed into a socio-economic issue about comparative advantage. This study used the social combustion theory (SCT) proposed by Niu et al. (1993) [27] to present the framework of the potential driving factors of the CLOC. This theory extends the three essential conditions of natural combustion (burning material, combustion improver, and firing temperature) to the study of social problems, which are often used to analyze the internal formation mechanism of social and natural contradictions [28].

The analysis framework under the SCT is shown in Figure 3, and the preliminary selection of the driving factors are listed in Table 1 . The balance of the land supply can be seen as a furnace, and the combustion intensity depends on the extent to which this balance is broken. An excessively high CLOC rate undoubtedly destroys the system's stability and tends to have a lasting effect, so the CLOC rate can be regarded as the "burning material" of this system.

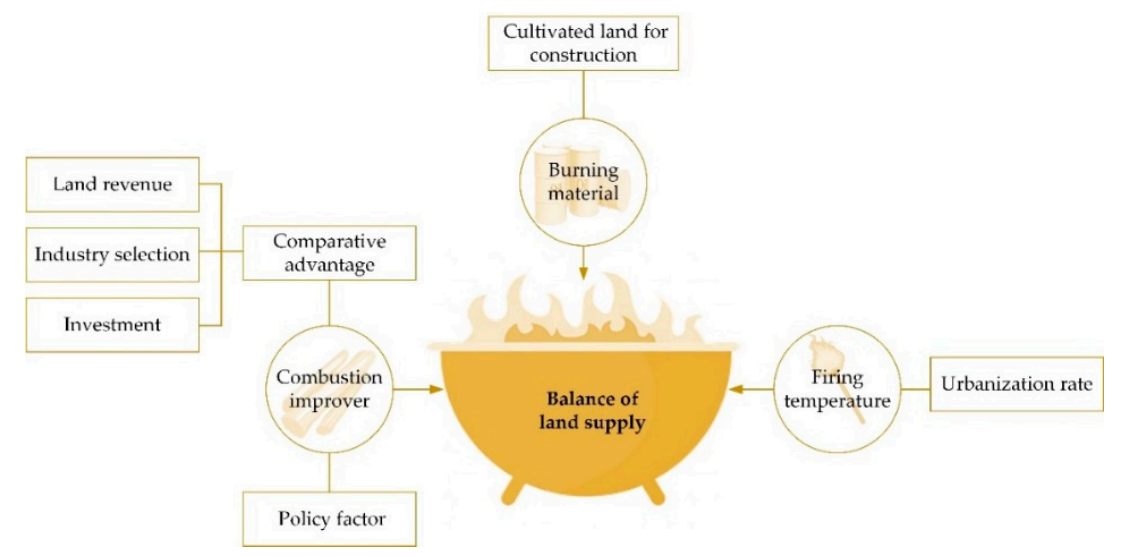

Figure 3. An analysis framework of the cultivated land occupation for construction (CLOC) from the viewpoint of social combustion theory.

Table 1. Primary selection of the driving factors of CLOC.

\begin{tabular}{|c|c|c|c|}
\hline Category & Variable & Description & Attribute \\
\hline Urbanization & $\begin{array}{l}\text { Population urbanization rate } \\
\text { (UR) }\end{array}$ & $\begin{array}{l}\text { The proportion of a region's urban population in the } \\
\text { total population. }\end{array}$ & Explanatory variable \\
\hline Industry selection & $\begin{array}{l}\text { The output value of the } \\
\text { tertiary industry } \\
\text { (VT) }\end{array}$ & $\begin{array}{l}\text { The total amount of income obtained by the government for } \\
\text { the transfer of state-owned construction land through land bid } \\
\text { invitations, auction and listing systems, etc. }\end{array}$ & Control variable \\
\hline Investment & $\begin{array}{l}\text { Fixed investment } \\
\text { (FI) }\end{array}$ & $\begin{array}{l}\text { Construction and acquisition of fixed assets measured in } \\
\text { monetary terms. }\end{array}$ & Control variable \\
\hline Policy factors & $\begin{array}{l}\text { Amount of state-owned } \\
\text { construction land supply } \\
\text { (LS) }\end{array}$ & $\begin{array}{l}\text { According to the annual land supply plan, the municipal or } \\
\text { county government provides the total amount of land used by } \\
\text { units or individuals through transfer, allocation, and leasing. }\end{array}$ & Control variable \\
\hline
\end{tabular}


The population urbanization rate acts as the firing temperature in this system (a main driving force of urban expansion and cultivated land loss in previous studies $[29,30])$. When the urban population reaches a peak, the balance of the land supply is inclined to reduce the cultivated land and increase the urban construction land to meet people's basic needs. From another perspective, the problem of the idle rural cultivated land caused by population migration also accelerates the CLOC rate. For instance, the rural-urban migration, which was considered to be the motivating power behind China's urbanization, was recognized to be responsible for the problem of "hollow villages", as many villagers chose to earn their livings in cities and have abandoned their original cultivated land [2], thereby creating the chance to convert spare cultivated land into construction land by the government [3].

Comparative advantage and policy factors play a role in aggravating contradictions and instability, serving as the "combustion improver" in the system. Comparative advantage is a key consideration for local governments when planning land use. Different production activities on the same land will yield different economic benefits, so the government often compares and predicts investment situations, industry development, and, more importantly, land income, in order to select the most valued activities that will generate higher marginal revenue in the future [31].

In comparing various land incomes, the fact remains that local governments in China often choose the revenue from land sales rather than returns from farming, thus promoting the CLOC rate to a large extent [32]. Second, the industrial structure affects the conversion of cultivated land by changing land-use efficiency [33]. Compared with industrial enterprises, which belong to China's secondary industry, enterprises from tertiary industries, such as educational and cultural enterprises, are mainly located in the central area of a city with a higher plot ratio, so they use relatively less construction land [34]. Third, the fixed investment has been incorporated into the driving mechanism of urban expansion by many scholars $[20,23]$. Unlike other economic factors, fixed investment directly reflects the scale and pace of investment in buildings and factories $[35,36]$.

For policy factors, the control of the non-agricultural use of farmland is an important component of public policies implemented by governments around the world, such as differential property taxation for farmland in Maryland [37], strict agricultural zoning in Hawaii [38], and agricultural land reserves in British Columbia [39]. In China, to balance the relationship between agricultural production and urbanization processes, the central government controls the quantity of cultivated land and urban construction land by making a land-use master plan regularly, which allocates construction land quotas to each province [2].

\subsubsection{Data Source and Processing}

The land-related data (the cultivated land area occupied by construction, the total cultivated land area at the beginning of the year, the government revenue from land sales, and the amount of state-owned construction land) for each province were taken from the China Land and Resources Statistical Yearbook (2006-2017), with the missing data for each province (except Tibet) in 2011 and 2012 supplemented by the city's statistical yearbooks. The missing data in Tibet were supplemented by data from other years with the cubic exponential smoothing model. In addition, the population urbanization rate and the fixed investment can be accessed on the website of the National Bureau of Statistics of China (http://data.stats.gov.cn/english/).

2.2. Methods (Geode (1.12) and ArcMap (10.5) Software Were Used in ESDA (Including Outlier Analysis, Global and Local Spatial Autocorrelation), and the Spatial Regression Analysis Was Performed by MATLAB (R2016a) Software)

\subsubsection{Global Spatial Autocorrelation}

Global spatial autocorrelation refers to the clustering degree of a phenomenon in space from an overall perspective, which is based on the null hypothesis of the random spatial distribution of research objects [40]. The most commonly used index for judgment is the Global Moran's I index, 
which not only reveals the spatial clustering characteristics of CLOC but also acts as a precondition for adopting the spatial regression models in our study. The calculation formula of Global Moran's I index is as follows:

$$
\begin{gathered}
I_{g l o, i}=\frac{\sum_{i=1}^{n} \sum_{j=1}^{n} w_{i j}\left(X_{i}-\bar{X}\right)\left(X_{j}-\bar{X}\right)}{S^{2} \sum_{i=1}^{n} \sum_{j=1}^{n} w_{i j}}, \\
S^{2}=\frac{1}{n} \sum_{i=1}^{n}\left(X_{i}-\bar{X}\right)^{2}, \bar{X}=\sum_{i=1}^{n} X_{i}
\end{gathered}
$$

where $X_{i}$ and $X_{j}$ are the CLOC rates for the province $i$ and j. $S^{2}$ and $\bar{X}$ are the variance and the mean value of $X_{i}$, respectively. The parameter $w_{i j}$ denotes the element of $i$ row and $j$ column in a spatial weight matrix, and $n$ represents the number of cross-sections ( 31 in this study).

The values of the global Moran's I index $\left(I_{g l o}\right)$ fall between the interval $(-1,1)$. At a certain significance level, the CLOC rate shows a positive spatial association in spatial distribution if $I_{g l o}$ is above 0 , showing that the neighboring provinces have a similar property in certain aspects, and a tendency toward dispersion can be seen if $I_{g l o}$ is below 0 . Note that if $I_{g l o}$ equals 0 , the CLOC rate shows a random spatial distribution, indicating that there is no spatial association among all the provinces.

\subsubsection{Local Spatial Autocorrelation}

To further describe the spatial distribution of a single province, we adopted the Local Moran's I index [22,41], which is as follows:

$$
I_{l o c, i}=\sum_{j=1}^{n} \frac{W_{i j}\left(X_{i}-\bar{X}\right)\left(X_{j}-\bar{X}\right)}{\sigma^{2}}, \bar{X}=\sum_{i=1}^{n} X_{i}
$$

where $\sigma^{2}$ is the variance of the variable $X$, and the other parameters have the same meanings as above.

According to the values of the Local Moran's I index, the Moran scatter plot can be drawn with four spatial distribution relationships between a single province and its neighbors (Figure 4). The first and third quadrants of the Moran scatter plot represent a high-high spatial cluster (the same high CLOC rates appeared in the neighboring provinces) and a low-low spatial cluster (the same low CLOC rates appeared in the neighboring provinces), respectively. The second and fourth quadrants are spatial outliers, including a low-high spatial outlier (a province with a high CLOC rate is surrounded by the low CLOC rates provinces) and high-low spatial outlier (a province with a low CLOC rate is surrounded by the high CLOC rates provinces), respectively, which are also called the "hot spot" and "cold spot". [42].
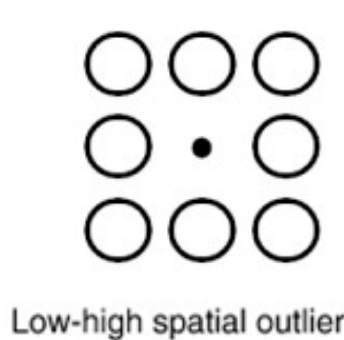

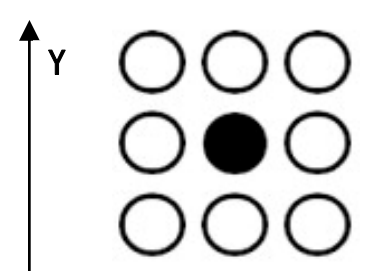

High-high spatial cluster

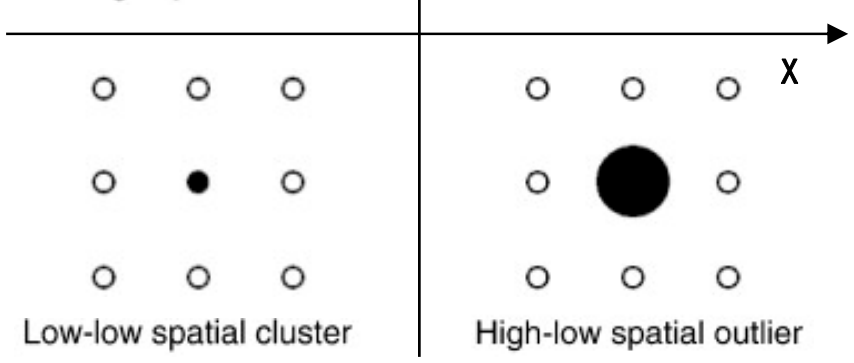

Figure 4. Four spatial distribution relationships in a Moran scatter plot. 


\subsubsection{The Spatial Weight Matrix}

The spatial weight matrix characterizes the dependence and association of spatial units. However, it cannot be estimated and needs to be set in advance [43]. Previous studies have shown that various settings of spatial weight may lead to different results in parameter estimation and hypothesis testing [44,45]. In order to ensure the robustness of the regression analysis results, we adopted three commonly used methods of spatial weights (Figure 5), which aimed at contiguity, geographic distance, and economy.

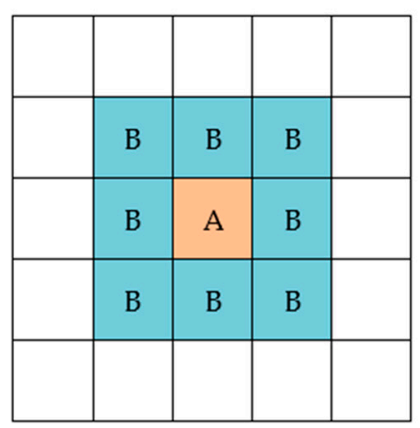

(a)

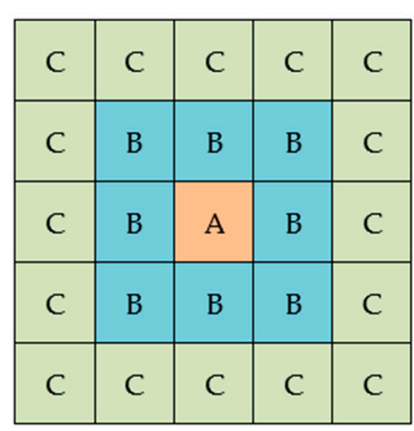

(b)

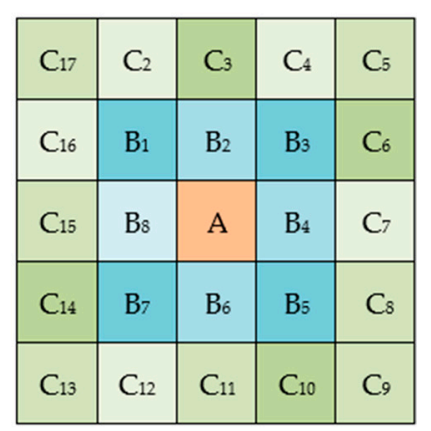

(c)

Figure 5. Defining spatial weight: (a) queen contiguity weight; (b) geographic distance weight; (c) economic distance weight.

\section{Queen contiguity weight}

The queen contiguity weight belongs to one of the first-order contiguity weights proposed by Berry and Marble (1968) [46]. Similar to the move of the "queen" in chess, two regions are defined as neighbors if they share a common edge or vertex [47]. The matrix expression is as follows:

$$
W_{q u e}=W_{i j}=\left\{\begin{array}{ll}
1, & \text { if region } i \text { and region } j \text { have the common edge or vertex } \\
0, & \text { otherwise }
\end{array} .\right.
$$

Although the queen contiguity weight has the limitation that the spatial dependence exists only between the interconnected spatial units, it highlights the importance of the adjacent neighbors, which closely matches the natural attribute of the cultivated land [48].

\section{Geographic distance weight (geo-distance weight)}

The geographic distance weight overcomes the shortcoming of the queen contiguity weight to some extent because it takes the distance-decay effect into account. This means that the farther apart the two spatial units are, the weaker the spatial association is, which is consistent with Tobler's first law of geography. Therefore, this type of weight is widely used in the research of various spatial relationships $[49,50]$. In this study, an inverse distance weight was established, which added the limitation of K-nearest neighbors ( $\mathrm{K}$ is a positive integer) to control the minimum number of neighbors in each province [51]. The expression is as follows:

$$
W_{\text {geo }}=W_{i j}=\left\{\begin{aligned}
1 / d_{i j,} & d_{i j} \leq \delta_{1} \text { and } k \geq \delta_{2} \\
0, & \text { otherwise }
\end{aligned}\right.
$$

where $d_{i j}$ represents the great-circle distance between province $i$ and $j$, which is calculated with the longitude and latitude data of China's provincial capitals. The parameter $k$ denotes the number of neighbors for a single province. Parameters $\delta_{1}$ and $\delta_{2}$ denote the distance threshold and the minimum number of neighbors, respectively, forming the cut-off condition of the weight effect together. To stop the value of the weight and the number of a province's neighbors becoming $0, \delta_{1}$ and $\delta_{2}$ were set to 
$800 \mathrm{Km}$ and 6, respectively. Under this setting, the average number of neighbors for 31 provinces was 8.23 , and the percentage of the spatial connectivity was $26.53 \%$.

3. Economic distance weight (eco-distance weight)

Apart from the geographic distance, economic and social factors have also been proven to influence the association among spatial units [45]. In fact, provinces with higher levels of economic development are more likely to trade with other provinces [52]. Therefore, the method of Wang et al. (2019) was adopted [53], which incorporated the per capita gross domestic product (GDP) for each province based on a geographic distance weight. The expression is as follows:

$$
\begin{gathered}
W_{\text {eco }}=W_{\text {geo }} \times \operatorname{diag}\left(\frac{\overline{X_{1}}}{\bar{X}}, \frac{\overline{X_{2}}}{\bar{X}}, \frac{\overline{X_{3}}}{\bar{X}}, \ldots, \frac{\overline{X_{n}}}{\bar{X}}\right), \\
\overline{X_{i}}=\frac{1}{t_{1}-t_{0}+1} \sum_{t_{0}}^{t_{1}} X_{i t}, \\
\bar{X}=\frac{1}{n\left(t_{1}-t_{0}+1\right)} \sum_{i=1}^{n} \sum_{t_{0}}^{t_{1}} X_{i t}
\end{gathered}
$$

where $W_{\text {geo }}$ is a geographic distance weight matrix and $\left(t_{1}-t_{0}+1\right)$ indicates the research period, with $t_{0}=2005$ and $t_{1}=2016 . \bar{X}_{i}$ and $\bar{X}$ represent the GDP per capita for the province $i$ and all the 31 provinces during the study period, respectively. It can be seen that a province with a higher per capita GDP will be given a similar higher weight value, which means that the more frequently the two provinces trade with each other, the stronger the spatial dependence between them will become.

\subsubsection{Spatial Econometrics Models}

The biggest difference between the spatial and non-spatial econometrics models is whether interaction effects are considered [54]. In addition, spatial regression models can be divided into several types according to different interaction effects. In this study, we followed the method of Elhorst (2010) [55] to select the appropriate regression analysis model.

There are three spatial regression models that are widely used in spatial interaction effect analysis. The spatial lag model (SLM) takes into account the endogenous interaction effect (WY) between dependent variables. This means that the dependent variable in a region is partially determined by the dependent variables from other neighboring regions. The spatial error model (SEM) considers the interaction effect $(W \phi)$ between the error terms, which means that the impact of the error term from the neighbors can be measured. In addition, these two models can be transformed into the spatial Durbin model (SDM), which contains both the endogenous interaction effect between dependent variables $(W Y)$ and the exogenous interaction effect between independent variables (WX), showing that the observations in this model are related to both dependent and independent variables of its neighbors. The three models are specified as follows:

$$
\begin{gathered}
\text { SLM }: Y_{i t}=\rho \sum_{j=1}^{N} W_{i j} Y_{j t}+\beta X_{i t}+\mu_{i}+v_{t}+\varepsilon_{i t} \\
\text { SEM }: Y_{i t}=\beta X_{i t}+\mu_{i}+v_{t}+\phi_{i t}, \quad \phi_{i t}=\lambda \sum_{j=1}^{N} W_{i j} \phi_{j t}+\varepsilon_{i t} \\
\mathrm{SDM}: Y_{i t}=\rho \sum_{j=1}^{N} W_{i j} Y_{j t}+\beta X_{i t}+\sum_{j=1}^{N} W_{i j} X_{j t} \theta+\mu_{i}+v_{t}+\varepsilon_{i t}
\end{gathered}
$$

where $Y_{i t}$ indicates the dependent variable (CLOC rate) for the province $i$ in the year $t$. $X_{i t}$ is a $(N T \times K)$ observation matrix of independent variables, with $N, T$ and $\mathrm{K}$ representing the number of provinces, the research period, and the five potential driving factors (UR, RS, VT, FI, and LS), respectively. The parameter $\beta$ is a $(K \times 1)$ vector of the regression coefficients we are interested in and $W_{i j}$ is a $(N \times N)$ spatial weight matrix. Parameter $\rho$ in Equations (6) and (8) are the spatial autoregressive coefficients, and $\theta$ in (8) is the spatial autocorrelation coefficient-all of which are the regression coefficients of the spatial interaction effect mentioned above. In addition, $\mu_{i}$ and $v_{t}$ denote a time-period fixed effect 
and an individual fixed effect, respectively (whether the fixed effect is needed will be discussed in Section 3.2.1), and $\varepsilon_{i t}$ is an independent and identically distributed (IID) error term.

Before the regression analysis, our study needs to follow a series of test procedures to find the most appropriate model [55]. First, we need to estimate the ordinary least square (OLS) model and verify the existence of spatial interaction effect by classic Lagrange multiplier tests (classic LM-tests) and robust Lagrange multiplier tests (robust LM-tests) [56,57].

Second, to control the endogeneity problem during the regression analysis, the proper fixed-effect should be incorporated into the model by comparing the regression results under four effect types (non-fixed effect, time-period fixed effect, individual fixed effect, and dual fixed effect). The non-spatial OLS model, including both individual and time-period fixed effects, is as follows:

$$
Y_{i t}=\beta_{0}+\beta_{1} U R_{i t}+\beta_{2} R S_{i t}+\beta_{3} V T_{i t}+\beta_{4} F I+\beta_{5} U R_{i t}+\mu_{i}+v_{t}+\varepsilon_{i t}
$$

where all the variables are taken as natural logarithms for the purpose of explaining the coefficients as elasticities, and the parameters have the same meanings as those above.

Third, the selection of the three spatial models needs to be verified by two null hypotheses, (10) and (11), through the Wald test and the likelihood ratio (LR) test. If both hypotheses are rejected, the spatial Durbin is the best choice. Conversely, if the hypothesis (10) cannot be rejected and the result of a robust LM-test also points to the spatial lag model, then we should choose SLM. Similarly, if hypothesis (11) cannot be rejected and the result of the robust LM-test also pointed to the spatial error model, then SEM will be the most appropriate one to describe the data:

$$
\begin{gathered}
H_{0}^{1}: \theta=0 \\
H_{0}^{2}: \theta=-\rho \beta .
\end{gathered}
$$

It should be noted that the marginal effects of independent variables in spatial models need to be separated into direct effects and indirect effects (or spatial spillover effect). This is also one of the advantages of spatial models, which reveals the underlying spatial interaction effect of independent variables in different regions. Specifically, the variation of an independent variable in a particular unit not only affects the dependent variable in that region itself but also affects the dependent variables in other regions. The former is called a direct effect, while the latter an indirect effect [58].

\section{Results}

\subsection{Exploratory Spatial Data Analysis of CLOC}

\subsubsection{Outlier Analysis}

The appearance of an outlier often leads us to focus on the distribution characteristics of a certain region, and so the visualization of extreme values tends to be the beginning of ESDA. In this section, we used the box plot and the quantile map to explore the data characteristics of the CLOC rate.

Figure 6 shows the changes in CLOC rates over 12 years in 31 provinces, including the mean, median, and extreme outliers (below $Q_{1}-3 I Q R$ and above $Q_{3}+3 I Q R$, where IQR is the interquartile range), with the specific values shown in Table 2. 


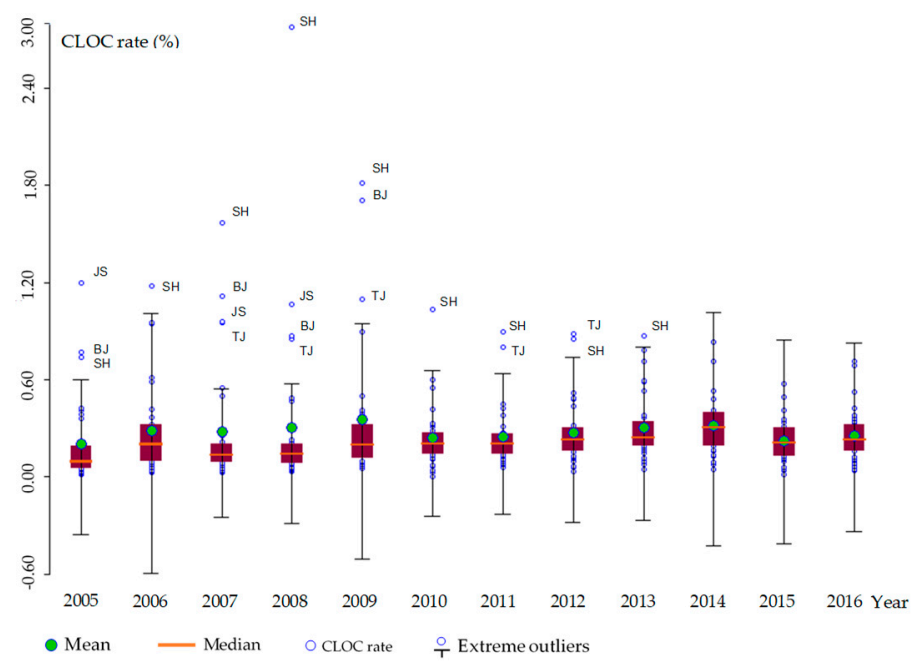

Figure 6. Box plot (Hinge = 3) for the CLOC rate from 2005 to 2016.

Table 2. The statistical description of the CLOC rate in the box plot.

\begin{tabular}{ccccccccccccc}
\hline Year & $\mathbf{2 0 0 5}$ & $\mathbf{2 0 0 6}$ & $\mathbf{2 0 0 7}$ & $\mathbf{2 0 0 8}$ & $\mathbf{2 0 0 9}$ & $\mathbf{2 0 1 0}$ & $\mathbf{2 0 1 1}$ & $\mathbf{2 0 1 2}$ & $\mathbf{2 0 1 3}$ & $\mathbf{2 0 1 4}$ & $\mathbf{2 0 1 5}$ & $\mathbf{2 0 1 6}$ \\
\hline Min & 0.013 & 0.024 & 0.025 & 0.031 & 0.053 & 0.001 & 0.059 & 0.030 & 0.042 & 0.046 & 0.014 & 0.036 \\
Max & 1.197 & 1.180 & 1.570 & 2.777 & 1.813 & 1.036 & 0.893 & 0.884 & 0.869 & 0.835 & 0.575 & 0.711 \\
$Q_{1}$ & 0.051 & 0.093 & 0.090 & 0.081 & 0.115 & 0.142 & 0.140 & 0.156 & 0.190 & 0.190 & 0.126 & 0.158 \\
Median & 0.093 & 0.200 & 0.134 & 0.138 & 0.196 & 0.202 & 0.201 & 0.229 & 0.242 & 0.304 & 0.210 & 0.227 \\
$Q_{3}$ & 0.188 & 0.322 & 0.203 & 0.204 & 0.323 & 0.270 & 0.264 & 0.301 & 0.343 & 0.397 & 0.306 & 0.324 \\
IQR & 0.137 & 0.230 & 0.113 & 0.123 & 0.208 & 0.129 & 0.124 & 0.145 & 0.152 & 0.207 & 0.180 & 0.166 \\
Mean & 0.203 & 0.285 & 0.280 & 0.307 & 0.354 & 0.244 & 0.250 & 0.274 & 0.306 & 0.316 & 0.223 & 0.256 \\
SD & 0.268 & 0.289 & 0.370 & 0.526 & 0.439 & 0.199 & 0.185 & 0.201 & 0.207 & 0.177 & 0.132 & 0.164 \\
\hline
\end{tabular}

Note: The unit of the CLOC rate is \%. IQR means the interquartile range.

From the mean, the overall change in the CLOC rates in 12 years was relatively stable, with the peaks occurring in 2009 and 2014. Secondly, the gap of the CLOC rates between provinces was fairly obvious before 2012 (the most significant year was 2009) and gradually narrowed after 2012, with the extreme outliers disappearing after 2014. In addition, the provinces with the highest frequencies of extreme outliers were Shanghai (SH), Beijing (BJ), Tianjin (TJ), and Jiangsu (JS), which are both economically developed and densely populated provinces in China. The CLOC rates of these four provinces were considerably higher than those of the other provinces before 2012.

In order to describe the situation of each province, the quantile map (Figure 7) was used for further analysis. Based on the statistical description in Table 2, we chose 6 years with roughly equal time intervals and divided the CLOC rate into seven levels from I to VII. The number of provinces matched with each level is shown in the lower left corner of each map. To be specific, for the majority of provinces in the early years, the CLOC rates were relatively low and concentrated in level II and III $(<0.2 \%)$, with some high values appearing in southeast China. After 2012, it seems that the CLOC rates of all provinces increased, with the figure gathering around level IV and V $(0.2-0.8 \%)$. In addition, the number of provinces with low values (I, II) and high values (VI, VII) dramatically declined after 2012. 


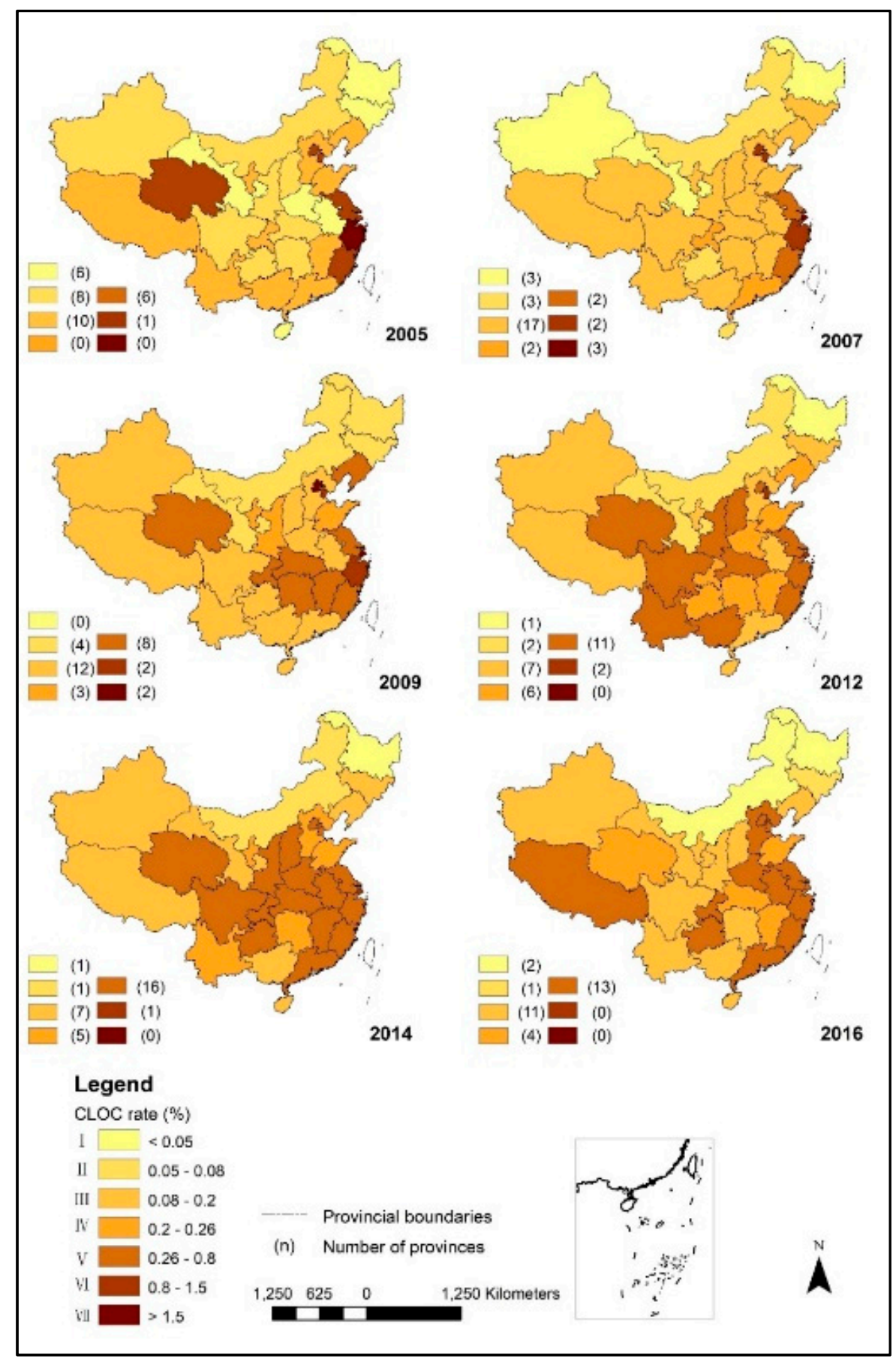

Figure 7. Quantile map for the CLOC rate from 2005 to 2016.

\subsubsection{Global Association}

The outlier analysis showed us the preliminary space-time distribution of the CLOC rate during the research period. After that, whether or not the distribution of the CLOC rate is random should be tested. The results of the Moran's I index and Z-score (standard deviations) under the three spatial weights are shown in Table 3. Except for the insignificant results in 2011 and 2012 (possibly related to the missing data for these two years), the index values were all between 0 and 1 , reflecting significant and positive spatial autocorrelation among 31 provinces. 
Table 3. The Moran's I index for spatial autocorrelation in the CLOC rate.

\begin{tabular}{cllllll}
\hline Year & \multicolumn{2}{c}{ Queen Contiguity } & \multicolumn{2}{c}{ Geo-Distance } & \multicolumn{2}{c}{ Eco-Distance } \\
\hline 2005 & $0.3928^{* * *}$ & $(4.0909)$ & $0.2000^{* * *}$ & $(2.9932)$ & $0.2466^{* * *}$ & $(3.5274)$ \\
2006 & $0.5365^{* * *}$ & $(5.1662)$ & $0.3574^{* * *}$ & $(4.7324)$ & $0.4071^{* * *}$ & $(5.2468)$ \\
2007 & $0.4727^{* * *}$ & $(4.7389)$ & $0.2650^{* * *}$ & $(3.7324)$ & $0.3302^{* * *}$ & $(4.4708)$ \\
2008 & $0.3208^{* * *}$ & $(4.4665)$ & $0.1954^{* * *}$ & $(3.8544)$ & $0.2393^{* * *}$ & $(4.4799)$ \\
2009 & $0.3639^{* * *}$ & $(3.7965)$ & $0.163^{* * *}$ & $(2.5071)$ & $0.2026^{* * *}$ & $(2.9601)$ \\
2010 & $0.3664^{* * *}$ & $(3.9904)$ & $0.2342^{* * *}$ & $(3.5678)$ & $0.2700^{* * *}$ & $(3.9717)$ \\
2011 & $0.1445^{*}$ & $(2.1084)$ & $0.0779^{*}$ & $(1.9284)$ & $0.0797^{*}$ & $(1.8255)$ \\
2012 & $0.2162^{* *}$ & $(2.5831)$ & $0.0466^{*}$ & $(1.8769)$ & $0.0542^{*}$ & $(1.7518)$ \\
2013 & $0.3903^{* * *}$ & $(3.7343)$ & $0.1895^{* * *}$ & $(2.6246)$ & $0.21911^{* * *}$ & $(2.9263)$ \\
2014 & $0.4994^{* * *}$ & $(4.7190)$ & $0.3448^{* * *}$ & $(4.4746)$ & $0.3724^{* * *}$ & $(4.7246)$ \\
2015 & $0.6053^{* * *}$ & $(5.5532)$ & $0.3886^{* * *}$ & $(4.9018)$ & $0.4118^{* * *}$ & $(5.0896)$ \\
2016 & $0.4090^{* * *}$ & $(3.9338)$ & $0.1881^{* * *}$ & $(2.6311)$ & $0.1686^{* * *}$ & $(3.1605)$ \\
\hline
\end{tabular}

Note: $* * * * *$, and ${ }^{*}$ indicate significance at the $1 \%, 5 \%$, and $10 \%$ levels, respectively. The $z$-score is in parentheses.

Furthermore, the results under the eco-distance weight were greater than those under the geo-distance weight (the results under the queen contiguity weight were not comparable due to their different initial settings), indicating that not only the geographic distance but also the economic factors affect the spatial pattern of the CLOC rate. This also suggested the rationality of incorporating economic factors (per capita GDP) into the geo-distance weight, which laid the foundation for the analysis of the spatial Durbin model.

\subsubsection{Local Association}

The results of the local Moran's I index are shown in Figure 8. Similarly, the year 2012 remains the dividing line before which most provinces were concentrated in the third quadrant, showing a trend of low-low spatial clusters, while only a few provinces were located in the first quadrant with high-high spatial clusters. After 2012, the number of high-high spatial clusters in the first quadrant started to rise, reaching a balance with low-low clusters in the third quadrant in 2016. In addition, "hot spots" (high-low spatial outliers) and "cold spots" (low-high spatial outliers) in the second and fourth quadrant, respectively, also showed an upward trend after 2012. Overall, although there were few hot or cold spots for the CLOC rate, the local spatial pattern of the CLOC rate was still characterized by spatial clusters, meaning that, locally, neighbors of a province with a high (low) CLOC rate tended to have the same high (low) values.

Figure 9 shows us the location of the spatial clusters and outliers. It can be seen that the high-high spatial clusters of the CLOC rate were mainly distributed in the southeastern coastal area, including Shanghai (SH), Jiangsu (JS), and Zhejiang (ZJ). These provinces belong to the Yangtze river delta, which is an urban agglomeration with the largest population in China, showing the importance of the population factor to CLOC rates' clustering. On the other hand, low-low spatial clusters were mainly distributed in the northeast and northwest China, including Neimenggu (NM), Ningxia (NX), Heilongjiang (HL), and Liaoning (LN). Compared with the coastal provinces mentioned above, these inland provinces relied heavily on traditional industries and agriculture. Moreover, the tertiary industry in those provinces was relatively backward, which led to massive population outflows [59]. In addition, except for Qinghai (QH), which was a cold spot in 2014, all the hot spots and cold spots in Figure 8 were not significant ( $p$-value $>0.05$ ), indicating that the CLOC rates were still characterized by spatial clusters in local areas. 

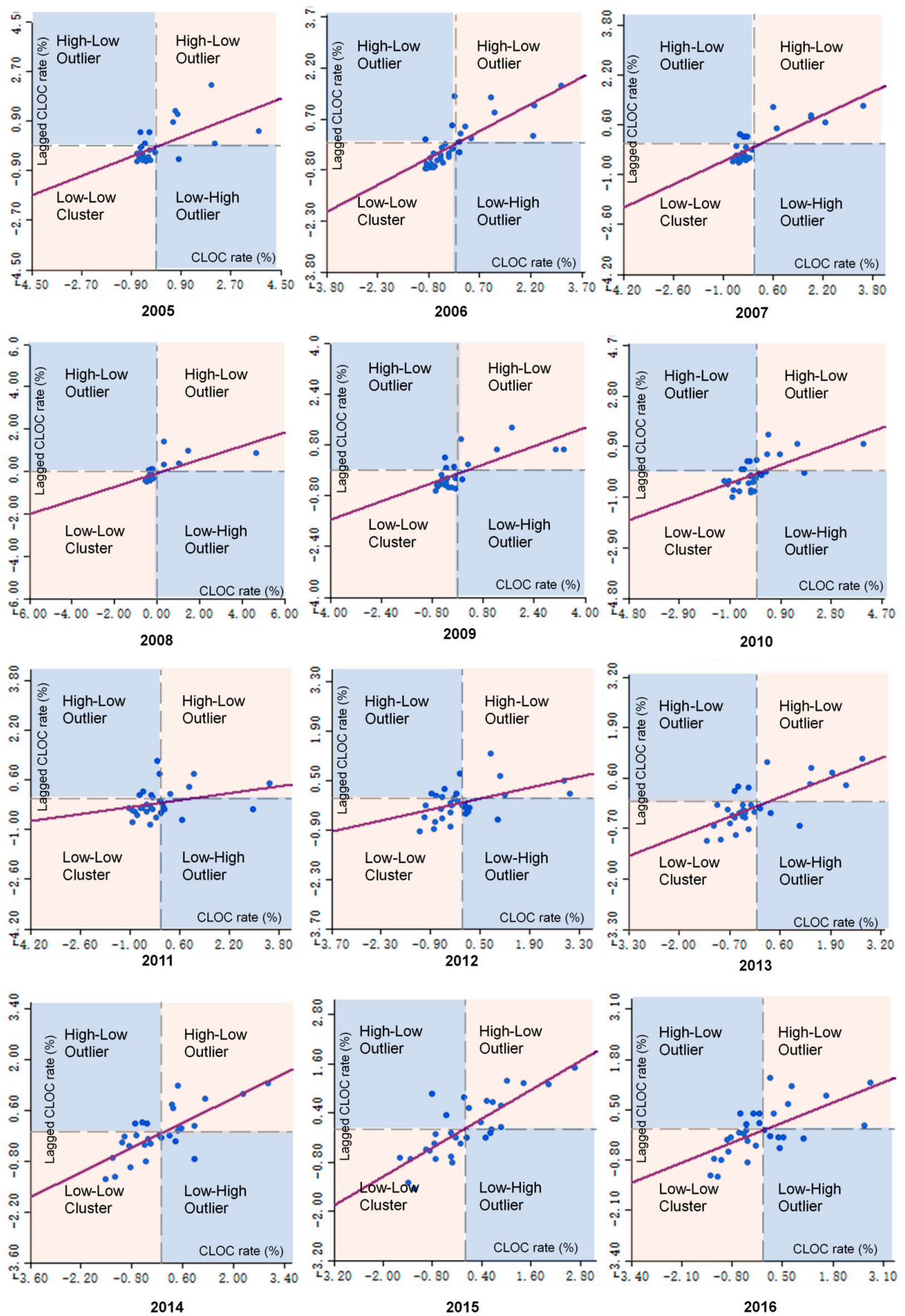

Figure 8. The Moran scatter plot of the CLOC rate (2005-2016). 


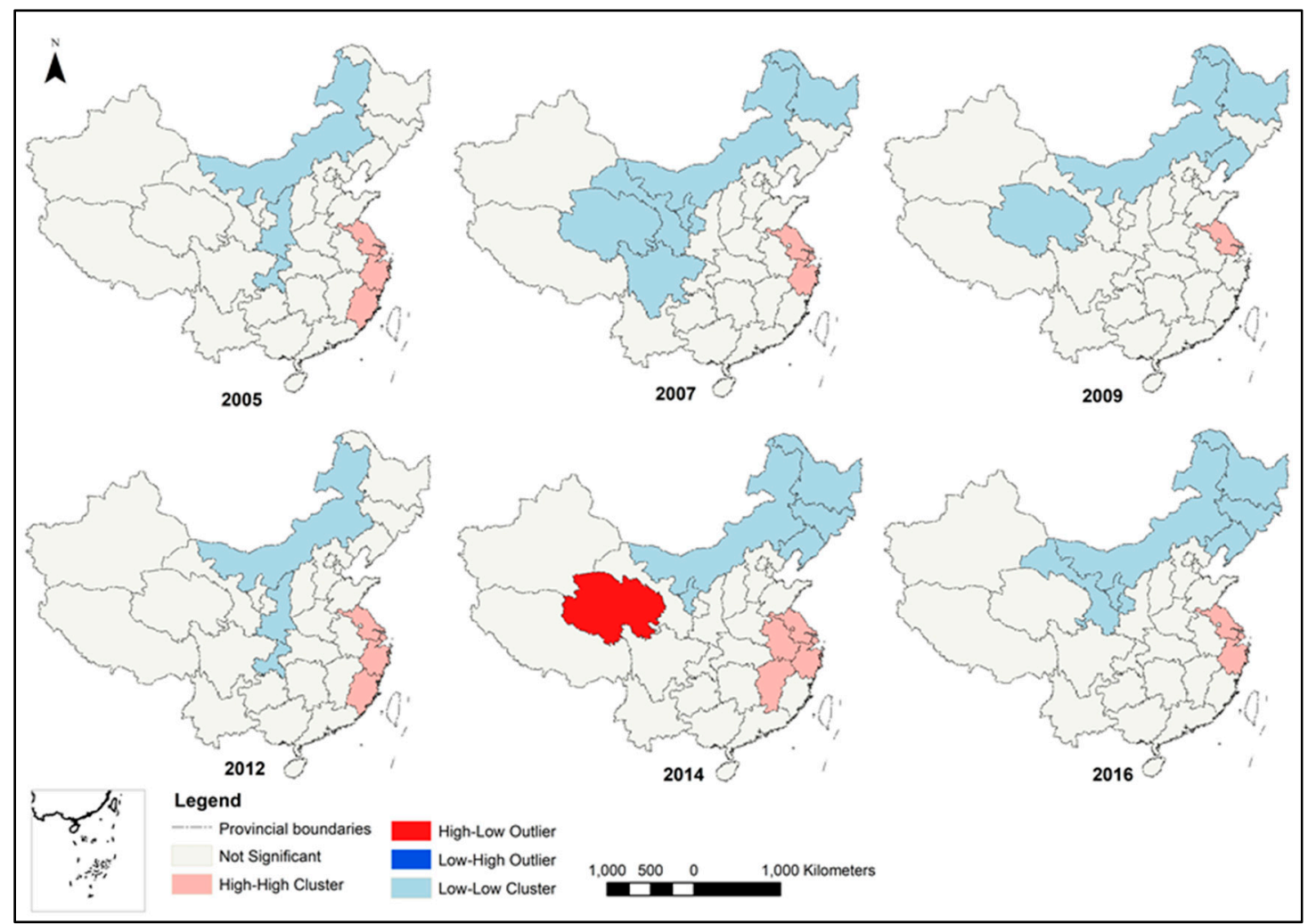

Figure 9. The local indicators for spatial association (LISA) map of CLOC rate ( $p$-value $\leq 0.05)$.

\subsection{The Driving Force Analysis}

\subsubsection{The Non-Spatial Regression Model Analysis}

In order to prove the necessity of introducing the spatial model and to select an appropriate one, we first established a non-spatial regression model with 31 provinces over 12 years, with the results shown in Table 4.

Table 4. Results of the non-spatial regression model from 2005 to 2016.

\begin{tabular}{|c|c|c|c|c|}
\hline Variables & $\begin{array}{l}\text { Non-Fixed Effect } \\
\text { (NF) }\end{array}$ & $\begin{array}{c}\text { Time-Period } \\
\text { Fixed Effect (TPF) }\end{array}$ & $\begin{array}{l}\text { Individual Fixed Effect } \\
\text { (IF) }\end{array}$ & $\begin{array}{l}\text { Dual Fixed Effect } \\
\text { (DF) }\end{array}$ \\
\hline Intercept & $9.183^{* * *}$ & & & \\
\hline UR & $1.031^{* * *}$ & $1.072 * * *$ & $1.984^{* * *}$ & $2.125^{* * *}$ \\
\hline FI & -0.060 & 0.085 & $0.808^{* * *}$ & $0.833^{* * *}$ \\
\hline VT & $-0.276 * *$ & $-0.366^{* *}$ & $-1.266^{* * *}$ & $-0.353^{* *}$ \\
\hline RS & $0.545^{* * *}$ & $0.562 * * *$ & $0.184^{* * *}$ & $0.206^{* * *}$ \\
\hline LS & $-0.207^{* *}$ & $-0.271^{* * *}$ & $0.014 * *$ & -0.066 \\
\hline R-squared & 0.413 & 0.446 & 0.765 & 0.797 \\
\hline Adjusted R-squared & 0.403 & 0.420 & 0.735 & 0.764 \\
\hline Log-likelihood & -342.364 & -333.289 & -200.076 & -197.425 \\
\hline LM test no spatial lag & $35.644^{* * *}$ & $25.612 * * *$ & $14.407^{* * *}$ & $18.256^{* * *}$ \\
\hline Robust LM test no spatial lag & $7.28^{* *}$ & $6.12 * *$ & $10.158^{* * *}$ & $12.46^{* * *}$ \\
\hline LM test no spatial error & $45.633 * * *$ & $30.368^{* * *}$ & $13.423 * * *$ & $17.142 * * *$ \\
\hline Robust LM test no spatial error & $9.997^{* * * *}$ & $4.944^{* *}$ & $11.094^{* * *}$ & $13.006^{* * *}$ \\
\hline
\end{tabular}

Note: ${ }^{* * *}, * *$ and ${ }^{*}$ indicate significance at the $1 \%, 5 \%$, and $10 \%$ levels, respectively. LM test means the Lagrange multiplier test. No spatial lag (error) means the possibility that no spatial interaction exists in dependent variables (residuals).

From the results of the classical and the robust LM test, it can be seen that all non-spatial models supported the existence of the two spatial interaction effects in the SLM and the SEM. Therefore, we preliminarily chose to establish the spatial Durbin model (SDM), which can be converted into the above two models. 
In terms of the goodness of fit, it is clear that the models with the individual fit (IF) effect $(73.5 \%)$ and the dual fixed (DF) effect (76.4\%) were approximately 35\% higher than the other two models. This proves the existence of unobservable variables that varied according to region, indicating that the individual fixed effects cannot be ignored in our model. In addition, a Hausman test was also conducted in this study to verify the existence of a fixed effect, with a chi-square statistic of 29.39, also rejecting the model without a fixed effect at a $1 \%$ significant level. Finally, only the IF effect was added to the following spatial Durbin model due to the non-significant result in the state-owned construction land supply (LS) under the DF effect.

Turning to the regression coefficient, the figure for the population urbanization rate (UR) was the highest, showing that for every $1 \%$ increase, the CLOC rate increased by approximately $2 \%$ on average. The fixed investment (FI) and the government revenue from land sales (LS) ranked second and third place, respectively. Moreover, the output value of the tertiary industry (VT) was the only variable that inhibited the CLOC rate, with the marginal effect at $-1.27 \%$.

The results of the Wald test and the likelihood ratio (LR) test are shown in Table 5. Note that both tests rejected the null hypothesis that the spatial Durbin model (SDM) can be converted into a spatial lag model (SLM) or a spatial error model (SEM) at a 1\% significance level, so the spatial Durbin model is still the best choice.

Table 5. Wald test and LR test for spatial model selection.

\begin{tabular}{ccc}
\hline Test & Statistic & Prob. \\
\hline Wald spatial lag & 62.007 & 0.000 \\
Wald spatial error & 49.372 & 0.000 \\
LR spatial lag & 58.023 & 0.000 \\
LR spatial error & 47.097 & 0.000 \\
\hline
\end{tabular}

Note: Wald (LR) Spatial lag (error) means that the Wald (LR) test for the spatial Durbin model against the spatial lag (error) model, and a probability greater than 0.05 points to insignificance.

\subsubsection{The Spatial Durbin Regression Model Analysis}

The results in Section 3.2.1 preliminarily verified the positive effect of the population urbanization rate on the CLOC rate and supported the necessity of expanding the non-spatial regression model into a spatial model. In this section, we further explore the impact of the driving factors on the CLOC rate by using the spatial Durbin model. Table 6 shows the changes in the goodness of fit under three spatial weights in the SDM. Note that we cannot judge the marginal effect of the explanatory variables from Table 6 because the coefficients of these variables here are not decomposed into the direct and the indirect effects, which include both the effects of the explanatory variables in the local province and the effects from other neighbors [55].

The fitting effect of the SDM was evaluated by the log-likelihood function value. Generally, the smaller the log-likelihood value is, the stronger the explanatory ability the model will have (because of the interference of the spatial factor, the goodness of fit cannot be directly used for the comparison between spatial and non-spatial models). The results in Table 6 show that the fitting effects of the three spatial models were better than those of the non-spatial model under the IF effect (see Table 4), with the values of log-likelihood improved by 11.67 (queen contiguity weight), 13.47 (eco-distance weight), and 16.54 (geo-distance weight). This result once again proves the rationality of adding the spatial effect.

The spatial autoregressive coefficient $\rho$ passed all the t-tests at a 5\% significant level under three spatial weights in the SDM. It proved that a province's CLOC rate is also significantly affected by those in neighboring provinces, supporting the original setting that there was an endogenous interaction effect between the dependent variables. In addition, the exogenous interaction effects between the independent variables (the coefficients of $\mathrm{W}^{*} \mathrm{X}$ in Table 6) were varied across the three spatial weights. The result under the geo-distance weight showed the best as all five independent variables passed the 
t-test at $10 \%$ significant level, while under the eco-distance weight and the queen contiguity weight, there were one and two variables failed in passing the test, respectively.

Table 6. The regression results of the spatial Durbin model from 2005 to 2016.

\begin{tabular}{ccccccc}
\hline Variables & \multicolumn{2}{c}{ Contiguity } & \multicolumn{2}{c}{ Eco-Distance } & \multicolumn{2}{c}{ Geo-Distance } \\
\hline UR & $2.569^{* * *}$ & $(3.501)$ & $2.489^{* * *}$ & $(3.586)$ & $2.517^{* * *}$ & $(3.650)$ \\
FI & $0.655^{* * *}$ & $(3.323)$ & $0.696^{* * *}$ & $(3.605)$ & $0.685^{* * *}$ & $(3.579)$ \\
VT & -0.565 & $(-1.500)$ & -0.432 & $(-1.109)$ & $-0.368^{* *}$ & $(-0.955)$ \\
RS & $0.165^{* *}$ & $(0.023)$ & $0.168^{* *}$ & $(2.358)$ & $0.168^{* *}$ & $(2.368)$ \\
LS & -0.079 & $(-1.031)$ & -0.072 & $(-0.953)$ & -0.074 & $(-0.986)$ \\
$\rho$ & $0.191^{* *}$ & $(2.527)$ & $0.276^{* * *}$ & $(3.284)$ & $0.272^{* * *}$ & $(3.168)$ \\
$W^{*}$ UR & $-1.251^{* *}$ & $(-2.257)$ & $-1.243^{* *}$ & $(-2.540)$ & $-1.336^{* * *}$ & $(-2.829)$ \\
$W^{*} \mathrm{FI}$ & 0.519 & $(1.432)$ & $0.788^{* *}$ & $(1.698)$ & $0.846^{* *}$ & $(1.894)$ \\
$\mathrm{W}^{*} \mathrm{VT}$ & -0.626 & $(-1.219)$ & -0.902 & $(-1.666)$ & $-0.934^{*}$ & $(-1.711)$ \\
$\mathrm{W}^{*} \mathrm{RS}$ & $-0.236^{* *}$ & $(-2.065)$ & $-0.290^{*}$ & $(-2.351)$ & $-0.411^{* * *}$ & $(-3.098)$ \\
$\mathrm{W}^{*} \mathrm{LS}$ & $0.093^{* * *}$ & $(2.660)$ & $0.076^{* * *}$ & $(2.783)$ & $0.082^{* * *}$ & $(3.310)$ \\
\hline R-squared & 0.785 & & 0.789 & & 0.793 & \\
Sample & 310 & & 310 & & 310 & \\
Log-likelihood & -188.403 & & -186.603 & & -183.536 & \\
\hline
\end{tabular}

Note: ${ }^{* * *}, * *$, and $*$ indicate significance at the $1 \%, 5 \%$, and $10 \%$ levels, respectively. Numbers in the parentheses represent $t$-statistic values.

In fact, the focus of our attention is the marginal contribution of the population urbanization rate and the other driving factors. Therefore, the coefficients (in Table 6) were converted into the direct effects and the indirect effects (in Table 7) to separately explain the spatial effects. In Table 7, we take the model under the geo-distance weight while considering that the three spatial weights had little difference and the results under the weight of the geographic distance had the best goodness of fit.

Table 7. Wald test and LR test for spatial model selection.

\begin{tabular}{|c|c|c|c|c|}
\hline Variables & Effect & Contiguity & Eco-Distance & Geo-Distance \\
\hline Urbanization rate (UR) & Indirect effect & $-1.131 * *$ & $-1.018^{* *}$ & $-1.256^{* *}$ \\
\hline \multirow[b]{2}{*}{ Fixed investment (FI) } & Direct effect & $0.678^{* * *}$ & $0.728^{* * *}$ & $0.733^{* * *}$ \\
\hline & Indirect effect & $0.143^{*}$ & $0.327^{* *}$ & $0.395 * *$ \\
\hline \multirow[t]{2}{*}{ Output value of tertiary industry (VT) } & Indirect effect & -0.229 & $-0.263 *$ & $-0.481^{* *}$ \\
\hline & Total & $-0.747 *$ & $-0.951 * *$ & $-1.283^{* *}$ \\
\hline \multirow[b]{2}{*}{ Government revenue from land sales (RS) } & Direct effect & $0.243 * *$ & $0.321 * *$ & $0.492 * *$ \\
\hline & Indirect effect & -0.146 & -0.139 & -0.152 \\
\hline
\end{tabular}

Note: ${ }^{* * *}, * *$ and ${ }^{*}$ indicate significance at the $1 \%, 5 \%$, and $10 \%$ levels, respectively.

Overall, the population urbanization rate had the greatest impact on the CLOC, showing that for every $1 \%$ increase in the population urbanization rate, the CLOC rate increased by an average of $1.398 \%$, supporting the initial setting as the core explanatory variable of the CLOC rate. The output value of the tertiary industry and the fixed investment ranked second and third place, with a marginal effect of $-1.283 \%$ and $1.128 \%$, respectively.

In terms of effect decomposition, the population urbanization rate considerably promoted the growth of the CLOC rate in the local province, while inhibiting those in the neighboring provinces. The related marginal effects were $2.654 \%$ (direct) and $-1.256 \%$ (indirect), respectively, which highlights 
the siphon effect of population on land conversion. It is believed that the central city gathered a majority of high-quality public service resources, such as employment, education, and medical care, so the labor force continued flowing out from the neighboring medium-sized and small cities, which slowed down the pace of land expansion in those cities [60].

The increase in fixed investment not only improved the CLOC rate in the local province but also promoted this land conversion in the neighboring provinces. To be specific, for every $1 \%$ increase in fixed investment, the CLOC rate in the local province and its neighbors increased by an average of $0.733 \%$ and $0.395 \%$, respectively. The positive spatial spillover effect of the fixed investment on the CLOC rate reflected the expansion of investment in China's land market and the resource reallocation of real estate [36].

The output value of the tertiary industry showed significant inhibition on the CLOC rate in both the local and neighboring provinces. Consistent with Pandey and Seto (2015) [34], there has been a high demand for land resources in the labor-intensive industries of developing countries for a long time. However, the prosperity and development of service industries (finance, education, cultural industries, etc.) have slowed down the conversion between the cultivated land and the construction land due to the higher land-use efficiency of these industries.

The government revenue from land sales promoted the increase in the CLOC rate in local provinces, but the impact on the neighboring provinces was not significant. The reason for this difference may be associated with the differential real estate control policies introduced by the central government [61]. For example, in Hainan Province, the central government has implemented restrictive policies on home purchases to reduce the local government's reliance on the real estate industry [62].

Compared to the insignificant inhibiting effect on the CLOC rate in local provinces, the amount of state-owned construction land supply had a positive spillover effect on the neighboring provinces, with a marginal effect of $0.362 \%$. This shows that the land supply policies or regulations implemented by the government failed to effectively resolve the contradiction between the cultivated land protection and the construction land expansion in the local province, thereby shifting the land demand to the neighboring provinces.

\subsubsection{The Changes in the Driving Factors in Two Periods}

In order to further reveal the reason why the CLOC rate of 31 provinces in Section 3.1 presented a "homogenized" clustering distribution after the year 2012, we divided the research period into Period 1 (2005-2011) and Period 2 (2012-2016). The regression results are shown in Table 8.

Table 8. The results of the effect comparison between two periods.

\begin{tabular}{ccccccc}
\hline Effect & Variables & \multicolumn{2}{c}{ Period 1 } & \multicolumn{2}{c}{ Period 2 } & Variation \\
\hline Direct effect & UR & $0.719^{* *}$ & $(2.034)$ & $2.800^{* * *}$ & $(2.158)$ & +++ \\
& FI & $0.952^{* * *}$ & $(2.574)$ & $0.545^{* *}$ & $(1.712)$ & - \\
& VT & 0.572 & $(0.720)$ & $-2.094^{* * *}$ & $(-2.813)$ & +++ \\
& RS & $0.151^{* *}$ & $(1.825)$ & $0.109^{* *}$ & $(1.993)$ & - \\
Indirect effect & LS & $-0.052^{*}$ & $(0.025)$ & $-0.087^{*}$ & $(0.685)$ & + \\
& UR & $-0.374^{* * *}$ & $(-2.108)$ & $-1.285^{* * *}$ & $(-2.343)$ & ++ \\
& FI & $1.188^{* * *}$ & $(2.242)$ & 0.036 & $(0.029)$ & -- \\
& VT & $-0.994^{*}$ & $(-0.645)$ & $-1.030^{* *}$ & $(1.734)$ & + \\
& RS & $-0.246^{* *}$ & $(-1.479)$ & $-0.582^{* *}$ & $(-1.387)$ & + \\
& LS & 0.391 & $(0.342)$ & $0.962^{* * *}$ & $(2.825)$ & ++ \\
\hline
\end{tabular}

Note: ***,**, and *indicate significance at the $1 \%, 5 \%$, and $10 \%$ levels, respectively. Numbers in the parentheses represent $t$-statistic values. Variation shows the change in coefficients in absolute value, and the symbol $-/+,--/+$ + , and $---/+++$ denote $(-0.5,0] /[0,0.5),(-1.5,-0.5] /[0.5,1.5)$ and $(-\infty,-1.5] /[1.5, \infty)$, respectively.

From the direct effect, we found that the fixed investment and the population urbanization rate ranked first $(0.952 \%)$ and second $(0.719 \%)$, respectively, in the marginal effect of the CLOC rate in Period 1. Moreover, it can be seen from Figure 10a that the pattern enclosed by the blue line is relatively 
small and square, indicating that the marginal effects of the driving factors in Period 1 had similar lower values. After entering Period 2, the population urbanization rate and the output value of the tertiary industry significantly increased their influence on the CLOC rate of the local province. The coefficients of the two reached $2.800 \%$ and $-2.094 \%$, respectively, becoming the most remarkable factors for the CLOC rate, with a spindle shape enclosed by the orange line in Figure 10a.

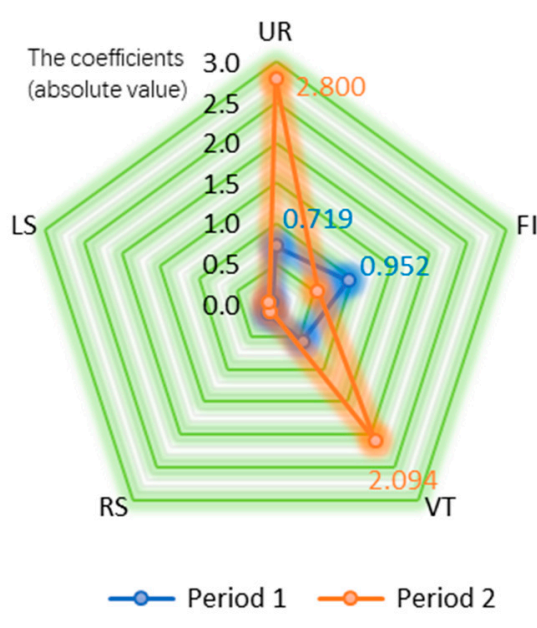

(a)

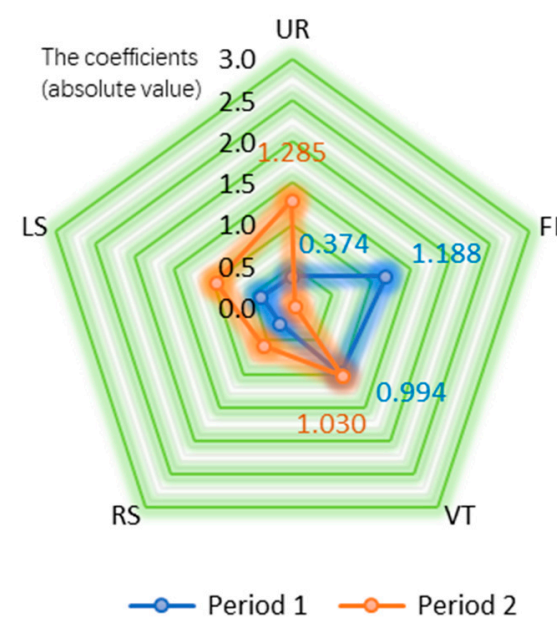

(b)

Figure 10. Variation of the direct effects (a) and indirect effects (b) of different variables between Period 1 and Period 2.

Turning to the indirect effect, we noticed that the fixed investment was still the dominant driving factor on the CLOC rate in Period 1 (Figure 10b), with a positive marginal effect at $1.188 \%$. However, this indirect effect became less significant in Period 2. In contrast, the indirect effect of the population urbanization rate increased dramatically in Period 2, showing that for every $1 \%$ increase in the population urbanization rate, there was a $1.285 \%$ decrease on average in the neighboring provinces' CLOC rates, which were obviously higher than $0.374 \%$ in Period 1.

\section{Discussion}

\subsection{Characteristics of Time and Space Distribution of CLOC}

Through exploratory spatial data analysis (ESDA), we found that cultivated land occupation for the construction (CLOC) of 31 provinces in China showed a significant spatial clustering characteristic from 2005 to 2016. The high-value clusters were mainly distributed in the southeastern coastal areas, while the clusters with low values located in the northeastern and the northwestern areas, which is consistent with the conclusions drawn by Wang et al. (2016) [48]. In addition, the CLOC rate showed a new trend of "homogenization" distribution in space after 2012, showing that the difference in CLOC rates among provinces is gradually narrowing, alongside a decreasing number of "cold and hot spots". The research hotspot "Shrinking Cities" in the field of city planning also supported this point from another angle $[63,64]$. The disparity between the east and the west cannot accurately summarize the current level of urbanization in China due to the continuous population migrations between cities. Instead of several large cities distributed in local areas, a rising number of city clusters equivalent in strength are emerging, thus narrowing the development difference of urbanization between cities.

\subsection{The Impact of Population Urbanization and Other Driving Factors}

The results of the spatial Durbin model showed us the spatial interaction effects including the direct and indirect effects of five driving factors on the CLOC rate. As the core explanatory variable, the population urbanization rate has promoted the growth of the CLOC rate in the local province while 
restraining the increase in the CLOC rate in the neighboring provinces. For control variables, the fixed investments had a positive effect on the CLOC rate for both the local province and the neighbors, while the output value of the tertiary industry, on the contrary, had a negative effect for both sides. The government revenue from land sales only contributed slightly to the rise of the CLOC rate for the local province, with a non-significant effect on the neighbors. In addition, the amount of state-owned construction land supply, which acted as a policy factor, slowed the increase in the CLOC rate in the local province but accelerated that rate in other neighbors. The indirect effects of these driving factors, to a large extent, are consistent with the conclusion drawn by Jiang et al. (2016) [60]. This shows that the positive spillover effect of explanatory variables mainly comes from market expansion and industrial reconfiguration, while the negative spillover effects are largely attributed to the migration and flow of production factors.

Moreover, this study further analyzed the changes in the driving factors that had a potential association with the "homogenization" spatial distribution of the CLOC rate after 2012. The results indicated that the CLOC rate in China experienced a transition from "investment-driven" to "populationand industry-driven", showing that the performance of the CLOC in China was mainly affected by fixed investments before 2012. Moreover, the marginal effect of the population urbanization rate and the output value of the tertiary industry had significantly improved since 2012, becoming the two dominant driving factors affecting the land conversion in China. In fact, this conclusion matches well with the development of China's urbanization. Extensive government investment was considered to be the main driving force behind China's early urbanization [65]. With the rising service industry (the tertiary industry) and the increasing population migrations among the cities, the early unbalanced development situation was broken, and the land resources as production factors were relatively evenly distributed in each province [66].

\subsection{Policy Recommendations}

Based on the above analysis, we put forward two suggestions on the issue of cultivated land occupation for construction (CLOC).

First, the government should dynamically adjust their distribution plan for construction land quotas with a trend of population migrations among provinces or even cities. The issue of construction land distribution is fairly important for the future pattern of the land market and, therefore, determines the development of the regional economy [2]. Although the large trans-provincial flow of the population has long attracted the attention of the central government, especially the resettlement of agricultural transfer population groups [67], the land policies related to this issue still lag behind, which was proven in our empirical analysis. At present, the construction land quotas cannot be accurately traded and used across provinces (only limited poverty-stricken areas are allowed), which means that the distribution of the construction land may not meet the needs of the increasing floating population, thereby causing a supply-demand imbalance in land markets and the problem of excessive housing prices [68].

Second, boosting the tertiary industry can also be seen as an effective approach to ease the contradiction between cultivated land and construction land in developing countries. Our analysis confirmed the positive role of the development of tertiary industry in improving land-use efficiency, thus slowing down the occupation of cultivated land in China. In most cases, scholars or officials have tended to deal with the issue of urban land expansion or rural cultivated land loss by using methods that sacrifice some economic benefits, such as limiting the local government's revenue from real estate [69], raising the tax burden of real estate enterprises [70], and transferring industrial enterprises located in urban areas [71]. Obviously, to some extent, all the measures above may help relieve the tension of land resources but damage the interests of some enterprises or other groups. In contrast, the development of a tertiary industry produces both a positive effect on the economy and mitigation of urban sprawl problem, which is a win-win result. In fact, some scholars have proven that the 
producer service industry contributes to both the development of the manufacturing industry and the intensive use of land [72,73].

\section{Conclusions}

This study focused on two issues. One was the changing trend of the spatial distribution of the CLOC for 31 provinces in China between 2005 and 2016, and the other was how the driving factors, including the population urbanization rate, affect this distribution and its changes. For the former, methods of exploratory spatial data analysis (ESDA) were used, including outlier analysis and global and local spatial autocorrelation analysis. For the latter, the spatial Durbin model was established to evaluate the spatial interaction effects of the driving factors, including direct and indirect effects on the CLOC rate. The results showed that the CLOC rate showed a significant clustering characteristic in space, and the population urbanization rate indicated a significant positive effect on the growth of the CLOC rate in the local province while inhibiting that rate for the neighboring provinces. Furthermore, a meaningful change was that the spatial distribution of the CLOC rate showed a new trend of "homogenization" after the year 2012, and behind this homogenization was a transformation from "investment-driven" models into "population-and industry-driven" models. Finally, this study suggested that the government should connect the changing trends of population migrations to the supply of the construction land quotas for each city. Further, promoting a tertiary industry in a city is more likely to achieve a win-win result when resolving the contradiction between cultivated land and construction land in a country with rapid urbanization trends.

Author Contributions: Z.M. conceptualized the framework of this study. K.L. contributed to the methodology, data collection, data calculation, and analysis of the results. J.L. revised the original manuscript. All authors read, revised, and approved the final version of the original manuscript. Moreover, several native English speakers contributed to the paper revision before submission.

Funding: This study was supported by the Fundamental Research Funds for the Central Universities of PR China (106112017CDJXSYY0001-KJYF201706 and 2017CDJSK03YJ05).

Acknowledgments: We thank Yingchao Lin (Chongqing University), Zongjian Lin (Nankai University) and Mingming Hu (Leiden University) for useful discussions. We thank Chunxi Li and Lifeng Jia for their continued care and support in our study.

Conflicts of Interest: The authors declare no conflict of interest.

\section{References}

1. Haberl, H. Competition for land: A sociometabolic perspective. Ecol. Econ. 2015, 119, 424-431. [CrossRef]

2. Li, Y.; Wu, W.; Liu, Y. Land consolidation for rural sustainability in China: Practical reflections and policy implications. Land Use Policy 2018, 74, 137-141. [CrossRef]

3. Liu, T.; Liu, H.; Qi, Y. Construction land expansion and cultivated land protection in urbanizing China: Insights from national land surveys, 1996-2006. Habitat Int. 2015, 46, 13-22. [CrossRef]

4. You, H.; Yang, X. Urban expansion in 30 megacities of China: Categorizing the driving force profiles to inform the urbanization policy. Land Use Policy 2017, 68, 531-551. [CrossRef]

5. Long, H.; Ge, D.; Zhang, Y.; Tu, S.; Qu, Y.; Ma, L. Changing man-land interrelations in China's farming area under urbanization and its implications for food security. J. Environ. Manag. 2018, 209, 440-451. [CrossRef] [PubMed]

6. Shao, Z.; Bakker, M.; Spit, T.; Janssen-Jansen, L.; Qun, W. Containing urban expansion in China: The case of Nanjing. J. Environ. Plan. Manag. 2019, 62,1-21. [CrossRef]

7. Chen, J.; Gao, J.; Chen, W. Urban land expansion and the transitional mechanisms in Nanjing, China. Habitat Int. 2016, 53, 274-283. [CrossRef]

8. Song, W.; Deng, X. Effects of urbanization-induced cultivated land loss on ecosystem services in the North China Plain. Energies 2015, 8, 5678-5693. [CrossRef]

9. Song, W. Decoupling cultivated land loss by construction occupation from economic growth in Beijing. Habitat Int. 2014, 43, 198-205. [CrossRef] 
10. Liu, Y.; Yang, Y.; Li, Y.; Li, J. Conversion from rural settlements and arable land under rapid urbanization in Beijing during 1985-2010. J. Rural Stud. 2017, 51, 141-150. [CrossRef]

11. Deng, X.; Gibson, J.; Wang, P. Management of trade-offs between cultivated land conversions and land productivity in Shandong Province. J. Clean. Prod. 2017, 142, 767-774. [CrossRef]

12. Luo, T.; Tan, R.; Kong, X.; Zhou, J. Analysis of the Driving Forces of Urban Expansion Based on a Modified Logistic Regression Model: A Case Study of Wuhan City, Central China. Sustainability 2019, 11, 2207. [CrossRef]

13. Wang, J.; He, T.; Lin, Y. Changes in ecological, agricultural, and urban land space in 1984-2012 in China: Land policies and regional social-economical drivers. Habitat Int. 2018, 71, 1-13. [CrossRef]

14. Zhang, W.; Wang, M.Y. Spatial-temporal characteristics and determinants of land urbanization quality in China: Evidence from 285 prefecture-level cities. Sustain. Cities Soc. 2018, 38, 70-79. [CrossRef]

15. Liu, J.Y.; Zhan, J.Y.; Deng, X.Z. Spatio-temporal patterns and driving forces of urban land expansion in China during the economic reform era. AMBIO 2005, 34, 450-455. [CrossRef] [PubMed]

16. Liu, Y.; Wang, L.; Long, H. Spatio-temporal analysis of land-use conversion in the eastern coastal China during 1996-2005. J. Geogr. Sci. 2008, 18, 274-282. [CrossRef]

17. Li, X.; Zhou, W.; Ouyang, Z. Forty years of urban expansion in Beijing: What is the relative importance of physical, socioeconomic, and neighborhood factors? Appl. Geogr. 2013, 38, 1-10. [CrossRef]

18. Li, G.; Sun, S.; Fang, C. The varying driving forces of urban expansion in China: Insights from a spatial-temporal analysis. Landsc. Urban Plan. 2018, 174, 63-77. [CrossRef]

19. Zhang, L.; Lu, D.; Li, Q.; Lu, S. Impacts of socioeconomic factors on cropland transition and its adaptation in Beijing, China. Environ. Earth Sci. 2018, 77, 575. [CrossRef]

20. Lang, W.; Long, Y.; Chen, T. Rediscovering Chinese cities through the lens of land-use patterns. Land Use Policy 2018, 79, 362-374. [CrossRef]

21. Xia, C.; Zhang, A.; Wang, H.; Zhang, B.; Zhang, Y. Bidirectional urban flows in rapidly urbanizing metropolitan areas and their macro and micro impacts on urban growth: A case study of the Yangtze River middle reaches megalopolis, China. Land Use Policy 2019, 82, 158-168. [CrossRef]

22. Wang, K.; Qi, W. Space-time relationship between urban municipal district adjustment and built-up area expansion in China. Chin. Geogr. Sci. 2017, 27, 165-175. [CrossRef]

23. Li, Y.; Chen, C.; Wang, Y.; Liu, Y. Urban-rural transformation and farmland conversion in China: The application of the environmental Kuznets Curve. J. Rural Stud. 2014, 36, 311-317. [CrossRef]

24. Tan, Y.; Xu, H.; Zhang, X. Sustainable urbanization in China: A comprehensive literature review. Cities 2016, 55, 82-93. [CrossRef]

25. Yang, K.; Chen, B.; Du, H.; Tang, X. The contribution of cultivated land occupation by construction to China's economic growth. J. Geogr. Sci. 2011, 21, 897-908. [CrossRef]

26. Song, W.; Pijanowski, B.C. The effects of China's cultivated land balance program on potential land productivity at a national scale. Appl. Geogr. 2014, 46, 158-170. [CrossRef]

27. Niu, W.Y.; Lu, J.J.; Khan, A.A. Spatial Systems Approach to Sustainable Development: A Conceptual Framework. Environ. Manag. 1993, 17, 179-186. [CrossRef]

28. Niu, W.Y.; Harris, W.M. China: The forecast of its environmental situation in the 21st century. J. Environ. Manag. 1996, 47, 101-114. [CrossRef]

29. Deng, X.; Huang, J.; Rozelle, S.; Zhang, J.; Li, Z. Impact of urbanization on cultivated land changes in China. Land Use Policy 2015, 45, 1-7. [CrossRef]

30. Du, X.; Huang, Z. Ecological and environmental effects of land use change in rapid urbanization: The case of hangzhou, China. Ecol. Indic. 2017, 81, 243-251. [CrossRef]

31. Li, K.; Ma, Z.; Zhang, G. Evaluation of the Supply-Side Efficiency of China's Real Estate Market: A Data Envelopment Analysis. Sustainability 2019, 11, 288. [CrossRef]

32. Yoo, S.; Wagner, J.E. A review of the hedonic literatures in environmental amenities from open space: A traditional econometric vs. spatial econometric model. Int. J. Urban Sci. 2016, 20, 141-166. [CrossRef]

33. Wang, Y. The Challenges and Strategies of Food Security under Rapid Urbanization in China. Sustainability 2019, 11, 542. [CrossRef]

34. Pandey, B.; Seto, K.C. Urbanization and agricultural land loss in India: Comparing satellite estimates with census data. J. Environ. Manag. 2015, 148, 53-66. [CrossRef] [PubMed] 
35. Liang, Y.; Cai, W.; Ma, M. Carbon dioxide intensity and income level in the Chinese megacities' residential building sector: Decomposition and decoupling analyses. Sci. Total Environ. 2019, 677, 315-327. [CrossRef] [PubMed]

36. You, K.; Solomon, O.H. China's outward foreign direct investment and domestic investment: An industrial level analysis. China Econ. Rev. 2015, 34, 249-260. [CrossRef]

37. Pearson, L.J.; Pearson, L.; Pearson, C.J. Sustainable urban agriculture: Stocktake and opportunities. Int. J. Agric. Sustain. 2010, 8, 7-19. [CrossRef]

38. Bengston, D.N.; Fletcher, J.O.; Nelson, K.C. Public policies for managing urban growth and protecting open space: Policy instruments and lessons learned in the United States. Landsc. Urban Plan. 2004, 69, 271-286. [CrossRef]

39. Newman, L.; Powell, L.J.; Wittman, H. Landscapes of food production in agriburbia: Farmland protection and local food movements in British Columbia. J. Rural Stud. 2015, 39, 99-110. [CrossRef]

40. Anselin, L.; Sridharan, S.; Gholston, S. Using exploratory spatial data analysis to leverage social indicator databases: The discovery of interesting patterns. Soc. Indic. Res. 2007, 82, 287-309. [CrossRef]

41. Anselin, L. Local indicators of spatial association-LISA. Geogr. Anal. 1995, 27, 93-115. [CrossRef]

42. Zhang, C.; Luo, L.; Xu, W.; Ledwith, V. Use of local Moran's I and GIS to identify pollution hotspots of Pb in urban soils of Galway, Ireland. Sci. Total Environ. 2008, 398, 212-221. [CrossRef] [PubMed]

43. Leenders, R. Modeling social influence through network autocorrelation: Constructing the weight matrix. Soc. Netw. 2002, 24, 21-47. [CrossRef]

44. Laguna, F.; Eugenia Grillet, M.; Leon, J.R.; Ludena, C. Modelling malaria incidence by an autoregressive distributed lag model with spatial component. Spat. Spatio Temporal Epidemiol. 2017, 22, 27-37. [CrossRef] [PubMed]

45. Ma, Y.; Ji, Q.; Fan, Y. Spatial linkage analysis of the impact of regional economic activities on PM2.5 pollution in China. J. Clean. Prod. 2016, 139, 1157-1167. [CrossRef]

46. Berry, B.J.L.; Marble, D.F. Spatial Analysis: A Reader in Statistical Geography; Prentice-Hall: Upper Saddle River, NJ, USA, 1968.

47. Dubin, R.; Fotheringham, A.S.; Rogerson, P.A. Spatial weights. Sage Handb. Spat. Anal. 2009, 8, $125-158$.

48. Wang, Y.; Liu, Y.; Li, Y.; Li, T. The spatio-temporal patterns of urban-rural development transformation in China since 1990. Habitat Int. 2016, 53, 178-187. [CrossRef]

49. Yuan, Y.; Cave, M.; Zhang, C. Using Local Moran's I to identify contamination hotspots of rare earth elements in urban soils of London. Appl. Geochem. 2018, 88, 167-178. [CrossRef]

50. Herrera, M.; Mur, J.; Ruiz, M. A Comparison Study on Criteria to Select the Most Adequate Weighting Matrix. Entropy 2019, 21, 160. [CrossRef]

51. Anselin, L. Modern Spatial Econometrics in Practice: A Guide to GeoDa, GeoDaSpace and PySAL; GeoDa Press: Chicago, IL, USA, 2014.

52. Agiakloglou, C.; Karkalakos, S. A spatial and economic analysis for telecommunications: Evidence from the european union. J. Appl. Econ. 2009, 12, 11-32. [CrossRef]

53. Wang, Y.; Zhao, T.; Wang, J.; Guo, F.; Kan, X.; Yuan, R. Spatial analysis on carbon emission abatement capacity at provincial level in China from 1997 to 2014: An empirical study based on SDM model. Atmos. Pollut. Res. 2019, 10, 97-104. [CrossRef]

54. Manski, C.F. Identification of endogenous social effects: The reflection problem. Rev. Econ. Stud. 1993, 60, 531-542. [CrossRef]

55. Elhorst, J.P. Applied Spatial Econometrics: Raising the Bar. Spat. Econ. Anal. 2010, 5, 9-28. [CrossRef]

56. Anselin, L.; Bera, A.K.; Florax, R.; Yoon, M.J. Simple diagnostic tests for spatial dependence. Reg. Sci. Urban Econ. 1996, 26, 77-104. [CrossRef]

57. Anselin, L. Spatial Econometrics: Methods and Models; Springer Science \& Business Media: Berlin, Germany, 1988; Volume 4.

58. LeSage, J.; Pace, R.K. Introduction to Spatial Econometrics; Chapman and Hall/CRC: London, UK, 2009.

59. Tan, J.; Lo, K.; Qiu, F.; Liu, W.; Li, J.; Zhang, P. Regional economic resilience: Resistance and recoverability of resource-based cities during economic crises in Northeast China. Sustainability 2017, 9, 2136. [CrossRef]

60. Jiang, X.; Zhang, L.; Xiong, C.; Wang, R. Transportation and Regional Economic Development: Analysis of Spatial Spillovers in China Provincial Regions. Netw. Spat. Econ. 2016, 16, 769-790. [CrossRef] 
61. Cai, X.; Tsai, C.; Wu, W. Are they neck and neck in the affordable housing policies? A cross case comparison of three metropolitan cities in China. Sustainability 2017, 9, 542. [CrossRef]

62. Daksueva, O.; Lin, J.J. The Role of Provinces in Decision-Making Processes in China: The Case of Hainan Province. In Enterprises, Localities, People, and Policy in the South China Sea; Springer: New York City, NY, USA, 2018; pp. 77-96.

63. Li, H.; Mykhnenko, V. Urban shrinkage with Chinese characteristics. Geogr. J. 2018, 184, 398-412. [CrossRef]

64. Long, Y.; Wu, K. Shrinking cities in a rapidly urbanizing China. Environ. Plan. A 2016, 48, 220-222. [CrossRef]

65. Chao, Z.; Zhang, P.; Wang, X. Impacts of Urbanization on the Net Primary Productivity and Cultivated Land Change in Shandong Province, China. J. Indian Soc. Remote 2018, 46, 809-819. [CrossRef]

66. Lin, G.C. Toward a post-socialist city? Economic tertiarization and urban reformation in the Guangzhou metropolis, China. Eurasian Geogr. Econ. 2004, 45, 18-44. [CrossRef]

67. Xu, D.; Deng, X.; Guo, S.; Liu, S. Labor migration and farmland abandonment in rural China: Empirical results and policy implications. J. Environ. Manag. 2019, 232, 738-750. [CrossRef] [PubMed]

68. Wu, Y.; Mo, Z.; Peng, Y.; Skitmore, M. Market-driven land nationalization in China: A new system for the capitalization of rural homesteads. Land Use Policy 2018, 70, 559-569. [CrossRef]

69. Tu, L.; Padovani, E. A research on the debt sustainability of china's major city governments in post-land finance era. Sustainability 2018, 10, 1606. [CrossRef]

70. Wang, X.; Hui, E.; Sun, J. Population Aging, Mobility, and Real Estate Price: Evidence from Cities in China. Sustainability 2018, 10, 3140. [CrossRef]

71. Ma, M.; Ma, X.; Cai, W.G.; Cai, W. Carbon-dioxide mitigation in the residential building sector: A household scale-based assessment. Energy Convers. Manag. 2019, 198, 111915. [CrossRef]

72. Yuan, F.; Gao, J.; Wang, L.; Cai, Y. Co-location of manufacturing and producer services in Nanjing, China. Cities 2017, 63, 81-91. [CrossRef]

73. McDonald, J.F. Producer Services and Metropolitan Growth and Development. In Sources of Metropolitan Growth; Routledge: Abingdon, UK, 2017; pp. 125-146.

(C) 2019 by the authors. Licensee MDPI, Basel, Switzerland. This article is an open access article distributed under the terms and conditions of the Creative Commons Attribution (CC BY) license (http://creativecommons.org/licenses/by/4.0/). 